\title{
定常風成流の解析解とその適用範囲について AN ANALYTICAL SOLUTION OF STEADY WIND-DRIVEN WATER CURRENTS AND ITS APPLICATION
}

\author{
松本治彦 $1 \cdot$ 羽田野袈梁義 2 \\ Haruhiko Matsumoto and Kesayoshi Hadano \\ 1正会員 工博 宇部短期大学教授 人間生活科学研究所（テ755 山口県宇部市文京町5-40）

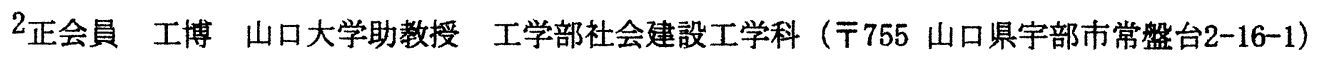

\begin{abstract}
This paper presents a theoretical study of the steady wind-driven currents in a semi-enclosed rectangular basin of uniform depth. Linearlised equations of motion and f-plane approximation are used. Horizontal component of winddriven current has been obtained for a general steady wind system by means of Fourie analysis. Solution is composed of both wind drift and slope current. Calculation reproduced a flow structure similar to the existing field data.
\end{abstract}

Key Words : wind-driven current, linearlised equation

1.はじめに

内湾や湖沼などの閉銷性の強い水域では，水の交換率 が悪いために，一度水質が污濁するとそれが長期化する 傾向がある. 一般に水質の予測は，水域の流れの特性を 知ることが不可欠である. また上記の水域の恒流は海上 を吹く風によって生じる風成流（ここでは，風により直 接起こされる吹送流と風の吹き寄せによって生じた海面 勾配による傾斜流を加えたものを風成流と定義する）が 主体となることが多い1).風成流の問題は取り扱う地形 が複雑であるために，単純な問題 ${ }^{2)}$ を除くと解析的に解 くことはなく，ほとんどの場合，計算機を用いた数值解 法によっている. このような数值解法は任意形状の水域 における種々の風条件に対する流れの3 次元分布を計算 することができる有力な方法である. 中村ら ${ }^{3)}$ は大村湾 の風成流について 3 次元数值シミュレーションを行い, Ekman spiral と類似な流況を再現している. その結果 は現地観測結果と比較的よく一致している.なお風速に 対する風成流の遅れ時間は現地観測では 3 時間程度であ るのに対して，数值計算では流速べクトルで12時間程度， 流速の絶対值で 3 時間程度となっている. 数值計算に見 られた流速べクトルと流速の絶対值の遅れ時間の差異は, はたして実現象でも生じるのか疑問が残る.また, 風速 に対する遅れ時間が比較的小さいことこら, 風系の変化 が稳やかな場合には風速をリアルタイムで変えた定常解 析の方法も考えられる。
以上のことを考慮して, 本研究では, 任意の定常な風 系により一様水深の矩形閉鎖水域に誘発される定常風成 流を理論解析し, 水平流速の 3 次元分布を表示する式を 求めている. また, 得られた解析解について渦動粘性俰 数の与え方を検討するとともに，解の適用範囲について 考察する.

\section{2. 基硠方程式}

図一1に示すように, 北緯 $\phi$ に位置し， $\mathrm{x}=0, \mathrm{a}, \mathrm{y}=0$, b を側岸線とする矩形閉塞海を設定する. この海上を長 時間, 定常的に風が吹き続けた場合に誘発される定常状

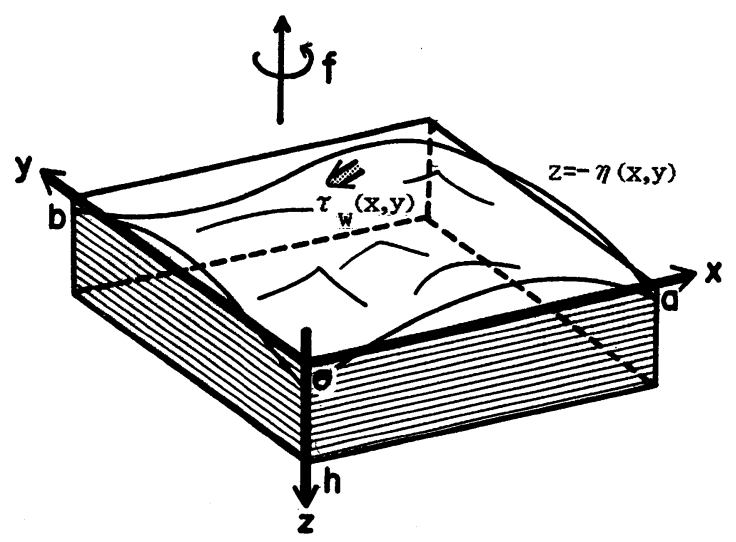

図ー1 モデルの概要と座標の設定 
態の海流を検討する. また，この現象は，f一平面近似 で十分な精度を持つ範囲内で起こるものとする．海水の 密度 力, コリオリカ, 重力, 摩擦力を考虑する. さらに, 水 平流に比へて鉛直流は微小であるとして, 静水圧の近似 を行う. 以上の仮定により線型化された運動方程式と連 続の式は，次式のようになる。

$0=f v-g \frac{\partial \eta}{\partial x}+A_{h}\left(\frac{\partial^{2} u}{\partial x^{2}}+\frac{\partial^{2} u}{\partial y^{2}}\right)+A_{z} \frac{\partial^{2} u}{\partial z^{2}}$
$0=-f u-g \frac{\partial \eta}{\partial y}+A_{h}\left(\frac{\partial^{2} v}{\partial x^{2}}+\frac{\partial^{2} v}{\partial y^{2}}\right)+A_{z} \frac{\partial^{2} v}{\partial z^{2}}$

$\frac{\partial}{\partial x} \int_{z--\eta}^{z=h} u d z+\frac{\partial}{\partial y} \int_{z=-\eta}^{z=h} v d z=0$

ここで, $u$ および $v$ は流速の $x$ および $y$ 方向成分, $f$ はコリオリパラメータ， $A_{h}$ は水平渦動粘性俰数， $A_{z}$ は 鉛直渦動粘性係数, $\mathrm{g}$ 仙重力加速度を表わす. 境界条 件として, 水表面 $z=-\eta(x, y)$ を $z=0$ と近似して $\left(-\rho A_{z} \frac{\partial u}{\partial z}\right)_{z=0}=\tau_{w x}(x, y)$

$\left(-\rho A_{2} \frac{\partial v}{\partial z}\right)_{z=0}=\tau_{w y}(x, y)$

とする. ここで, $\tau_{\mathrm{w}}(\mathrm{x}, \mathrm{y})$ および $\tau_{\mathrm{y}}(\mathrm{x}, \mathrm{y})$ は風灾力 の分布 $\vec{\tau}_{w}(x, y)$ の $x$ および $y$ 方向成分である. また,

簡単のため Donishiら ${ }^{4)} に$ にらい海底面では海水はすべ るとする. さらに鉛直境界壁では流速をぜロとする.

\section{3. 解析法の垃要と解析解}

解析法の概要は以下の通りである．まずストークスの 方法により，任意の定常風成流について風系と海面㑯斜 量により水平流速を表示する式を求める. 次に，流量流 線関数を導入してその支眍方程式を所与の定常風系に対 して解き，この結果を用いて海面㑯斜量を求める. 最後 に, 風系と海面㑯斜量により水平流速を表示する式に, 風系と海面傾斜量の結果を代入して水平流速を求める. 以下順を追って説明する.

[1] ストークスの方法により任意の定常風系に対して, 風系と海面傾斜量により水平流速を表示する式を求める. 海面㑯斜量 $\gamma_{x}=-\partial \eta / \partial x, \gamma_{y}=-\partial \eta / \partial y$ と水平 流速 $u, v$ の空間分布を複素数ベクトル表示して,

$$
\begin{aligned}
& \vec{W}(x, y, z)=u(x, y, z)+i v(x, y, z), \\
& \vec{\gamma}(x, y)=\gamma_{x}(x, y)+i \gamma_{y}(x, y) \text { とおくと, 式 }
\end{aligned}
$$

(1)，(2)は次のように表示される.

$A_{h}\left(\frac{\partial^{2} \vec{W}}{\partial x^{2}}+\frac{\partial^{2} \vec{W}}{\partial y^{2}}\right)+A_{z} \frac{\partial^{2} \vec{W}}{\partial z^{2}}-i f \vec{W}=-g \vec{\gamma}$

また, 風の応力分布 $\vec{\tau}_{w}(x, y)$ は海流と同形のフーリエ 級数で展開し，上述の手順で解く，その結果のみを以下 に示す。

$\vec{W}(x, y, z)=$

$\sum_{m=1}^{\infty} \sum_{n=1}^{\infty}\left\{\frac{\vec{L}_{m n}}{\rho \sqrt{A_{z} \vec{D}_{m n}}}\left[\left(\operatorname{coth} \sqrt{\frac{\vec{D}_{m n}}{A_{z}}} h\right) \cosh \sqrt{\frac{\vec{D}_{m n}}{A_{z}} z}\right.\right.$

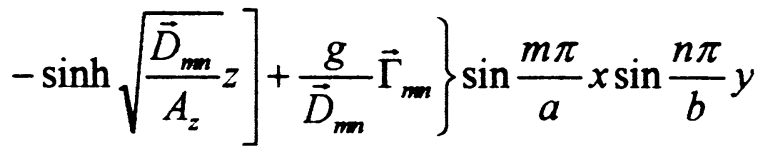

$\vec{\Gamma}_{m n}=\left(\frac{4}{a b}\right) \int_{0}^{a} \int_{0}^{b} \vec{\gamma}(x, y) \sin \frac{m \pi}{a} x \sin \frac{n \pi}{b} y d y d x$

$\vec{L}_{m n}=\left(\frac{4}{a b}\right) \int_{0}^{a} \int_{0}^{b} \vec{\tau}_{w}(x, y) \sin \frac{m \pi}{a} x \sin \frac{n \pi}{b} y d y d x$

$$
\vec{D}_{m m}=A_{h}\left[\left(\frac{m \pi}{a}\right)^{2}+\left(\frac{n \pi}{b}\right)^{2}\right]+i f
$$

[2] 流量流線関数を導入してその支的方程式を所与の 定常風系に対して解きこの結果を用いて海面傾斜量の 空間分布を求める. $\boldsymbol{x}, \boldsymbol{y}$ 方向の単位幅流量を $S_{x}=\int_{z=-\eta}^{z=h} u d z, S_{y}=\int_{z=-\eta}^{z=h} v d z$

とおくと，連続の式(3)は次のように表わされる.

$$
\frac{\partial S_{x}}{\partial x}+\frac{\partial S_{y}}{\partial y}=0
$$

式(11)より流量流線関数 せを定義することができる.

$$
S_{x}=\frac{\partial \Psi}{\partial y}, \quad S_{y}=-\frac{\partial \Psi}{\partial x}
$$

式(1)，(2)の両辺を皘分し， $\eta / h 《 1$ の条件を用いる 
と次式が得られる。

$0=f S_{y}-g h \frac{\partial \eta}{\partial x}+A_{h}\left(\frac{\partial^{2} S_{x}}{\partial x^{2}}+\frac{\partial^{2} S_{x}}{\partial y^{2}}\right)+\frac{\tau_{w x}(x, y)}{\rho}$

$0=-f S_{x}-g h \frac{\partial \eta}{\partial y}+A_{h}\left(\frac{\partial^{2} S_{y}}{\partial x^{2}}+\frac{\partial^{2} S_{y}}{\partial y^{2}}\right)+\frac{\tau_{w y}(x, y)}{\rho}$

式(12)，(13)および(14)より次式が得られる.

$\frac{\partial^{4} \Psi}{\partial x^{4}}+\frac{\partial^{4} \Psi}{\partial y^{4}}+2 \frac{\partial^{4} \Psi}{\partial x^{2} \partial y^{2}}=\frac{1}{\rho A_{h}}\left(\frac{\partial \tau_{w y}}{\partial x}-\frac{\partial \tau_{w x}}{\partial y}\right)$

これが流量流線関数の支配方程式である.ここで， $\vec{\tau}_{w}$ は海流と同形のフーリエ級数展開可能な形で与えること にする. さらに，式(15)において次の条件を課す.

$$
2 \frac{\partial^{4} \Psi}{\partial x^{2} \partial y^{2}}=0
$$

これは積分形の運動方程式(13)，(14)において,それぞれ $\frac{\partial^{2} S_{x}}{\partial x^{2}} \ll \frac{\partial^{2} S_{x}}{\partial y^{2}} \quad, \quad \frac{\partial^{2} S_{y}}{\partial y^{2}} \ll\left\langle\frac{\partial^{2} S_{y}}{\partial x^{2}}\right.$ と仮定したこ とになる. この条件設定に対する影響については，今後 の検討課題である.

また周辺境界壁では流速をぜロとしたことから，これ に沿って $\Psi$ は一定である.ささらに，この境界壁では $\mathrm{Sx}=0, \mathrm{Sy}=0$ となる. これらの条件を満たす $\Psi$ と して次式を得る.

$$
\begin{aligned}
& \Psi(x, y)=\sum_{m=1}^{\infty} \sum_{n=1}^{\infty}\left(\frac{1}{\frac{\mu_{m}{ }^{4}}{a^{4}}+\frac{\mu_{n}^{4}}{b^{4}}}\right) \times \\
& \left(\frac{1}{a b} \int_{0}^{a} \int_{0}^{b} \operatorname{curl}_{z} \vec{\tau}_{w}\left(\lambda, \lambda^{\prime}\right) X_{m}(\lambda) Y_{n}\left(\lambda^{\prime}\right) d \lambda^{\prime} d \lambda\right) \\
& \times X_{m}(x) Y_{n}(y)
\end{aligned}
$$

$$
\begin{aligned}
& X_{m}(x)=\cos \frac{\mu_{m}}{a} x-\cosh \frac{\mu_{m}}{a} x \\
& +\frac{\left(\sin \mu_{m}+\sinh \mu_{m}\right)\left(\sin \frac{\mu_{m}}{a} x-\sinh \frac{\mu_{m}}{a} x\right)}{\cos \mu_{m}-\cosh \mu_{m}}
\end{aligned}
$$

$$
\begin{aligned}
& Y_{n}(y)=\cos \frac{\mu_{n}}{b} y-\cosh \frac{\mu_{n}}{b} y \\
& +\frac{\left(\sin \mu_{n}+\sinh \mu_{n}\right)\left(\sin \frac{\mu_{n}}{b} y-\sinh \frac{\mu_{n}}{b} y\right)}{\cos \mu_{n}-\cosh \mu_{n}}
\end{aligned}
$$

である.

ただし， $\mu_{y}, \mu_{\mathrm{n}}$ は $\mathrm{y}=\cos \mathrm{x}$ と $\mathrm{y}=1 / \cosh \mathrm{x}$ の 二つの曲線交点のx座標を示す $(\mathrm{m}=1,2,3, \cdots, \mathrm{n}=$ $1,2,3, \cdots)$.

この解を式(13)，(14)より得られる次式に代入すると 海面傾斜量が得られる.

$$
\begin{aligned}
& -\frac{\partial \eta}{\partial x}=\frac{1}{g h}\left(2 \Omega \sin \phi \frac{\partial \Psi}{\partial x}-A_{h} \frac{\partial^{3} \Psi}{\partial y^{3}}-\frac{\tau_{w x}}{\rho}\right) \\
& -\frac{\partial \eta}{\partial y}=\frac{1}{g h}\left(2 \Omega \sin \phi \frac{\partial \Psi}{\partial y}+A_{h} \frac{\partial^{3} \Psi}{\partial x^{3}}-\frac{\tau_{w y}}{\rho}\right)
\end{aligned}
$$

なお, 風応力 $\vec{\tau}_{w}$ の与え方は後で示す.

[3] 風系と [2]で得た海面傾斜量を式(6)に代入して水平 流速の空間分布を求める. その計算式は以下のようであ る.

$$
\begin{aligned}
& \vec{W}(x, y, z)= \\
& \sum_{m=1}^{\infty} \sum_{n=1}^{\infty}\left\{\vec { P } _ { m n } \left[\left(\operatorname{coth} \sqrt{\frac{\vec{D}_{m m}}{A_{z}}} h\right) \cosh \sqrt{\frac{\vec{D}_{m n}}{A_{z}} z}\right.\right. \\
& -\sinh \sqrt{\left.\left.\frac{\vec{D}_{m m}}{A_{z}} z\right]+\frac{g}{\vec{D}_{m}} \vec{\Gamma}_{m n}\right\} \sin \frac{m \pi}{a} x \sin \frac{n \pi}{b} y}
\end{aligned}
$$

ここで,

$$
\vec{P}_{m n}=\frac{1}{\rho \sqrt{A_{z} \vec{D}_{m n}}}
$$

(18) $\times\left(\frac{1}{a b}\right) \int_{0}^{a} \int_{0}^{b} \vec{\tau}_{w}(x, y) \sin \frac{m \pi}{a} x \sin \frac{n \pi}{b} y d y d x$ 


$$
\begin{aligned}
& \vec{\Gamma}_{m n}=\left(\frac{4}{a b g h}\right) \times \\
& \int_{0}^{a} \int_{0}^{b}\left\{\left(2 \Omega \sin \phi \frac{\partial \Psi}{\partial x}-A_{h} \frac{\partial^{3} \Psi}{\partial y^{3}}-\frac{\tau_{w x}}{\rho}\right)\right. \\
& \left.+i\left(2 \Omega \sin \phi \frac{\partial \Psi}{\partial y}+A_{h} \frac{\partial^{3} \Psi}{\partial x^{3}}-\frac{\tau_{w y}}{\rho}\right)\right\} \\
& \times \sin \frac{m \pi}{a} x \sin \frac{n \pi}{b} y d y d x
\end{aligned}
$$

式(22)において $\vec{P}_{m n}$ のかかった項 $\vec{u} 1$ は風応力の直接の 作用による吹送流, そして $\vec{\Gamma}_{m n}$ のかかった項 $\vec{u} 2$ は $\operatorname{curl}_{z} \vec{\tau}_{w}$ を含む傾斜流を示す.

式中 $\vec{P}_{m n}$ と $g \vec{\Gamma}_{m n} / \vec{D}_{m n}$ は次のように表すことができる.

$$
\begin{aligned}
& \vec{P}_{m n}=\frac{1}{\rho \sqrt{A_{z}}\left(A^{2}+B^{2}\right)} \\
& \times\left\{\left(A L_{m m x}+B L_{m n y}\right)+i\left(A L_{m m y}-B L_{m n x}\right)\right\}
\end{aligned}
$$

$\frac{g \vec{\Gamma}_{m n}}{\vec{D}_{m n}}=\frac{g}{C_{1}^{2}+f^{2}}$

$\times\left\{\left(C_{1} \Gamma_{m m x}+f \Gamma_{m m y}\right)+i\left(C_{1} \Gamma_{m m y}-f \Gamma_{m m x}\right)\right\}$

ここで,

$$
\begin{aligned}
& C_{1}=A_{h}\left\{\left(\frac{m \pi}{a}\right)^{2}+\left(\frac{n \pi}{b}\right)^{2}\right\}, f=2 \Omega \sin \phi(27) \\
& A=\sqrt{\frac{C_{1}+\sqrt{C_{1}^{2}+f^{2}}}{2}}, \quad B=\frac{f}{2 A} \\
& \vec{L}_{m m}=L_{m m x}+i L_{m m y}, \vec{\Gamma}_{m n}=\Gamma_{m m x}+i \Gamma_{m m y}
\end{aligned}
$$

である.

水面に作用する風の応力分布 $\vec{\tau}_{w}(x, y)$ は, 次のバルク 公式5）を用いて推定する.

$$
\vec{\tau}_{w}(x, y)=\rho_{a} C_{f}\left|\vec{U}_{10}\right| \vec{U}_{10}
$$

ここで， $\rho_{a}$ は空気の密度である.したがって風の与え 方としては次のような手順をとる.
まず, 水面上 $10 \mathrm{~m}$ の風速分布を $\vec{U}_{10}(x, y)$ の関数形で 表現し，式(29)を用いて計算する.

$$
\vec{\tau}_{w}(x, y)=\tau_{w x}(x, y)+i \tau_{w y}(x, y)
$$

次に,

$$
\vec{\tau}_{w}(x, y)=\sum_{n=1}^{\infty} \sum_{m=1}^{\infty} \vec{L}_{m n} \sin \frac{m \pi}{a} x \sin \frac{n \pi}{b} y
$$

で

$\vec{L}_{m n}=$

$\frac{4}{a b} \int_{0}^{a} \int_{0}^{b} \vec{\tau}_{w}(x, y) \sin \frac{m \pi}{a} x \sin \frac{n \pi}{b} y d y d x$

を求めて式(6)に代入すればよい.

\section{4. 渦動粘性係数と水平流の分布}

以上で得られた解の基本的な特徴は前報6)で述べた。 ここでは渦動粘性俰数の与え方について検討する. 鉛直 渦動粘性係数 $\mathrm{A}_{2}$ について余越ら ${ }^{7)}$ は, 風速, 表面流速 およびせん断応力の関係より次のような推定式を与えて いる.

$$
A_{z}=0.00055 \sqrt{C_{f}} h U_{10}
$$

ここで， $\mathrm{U}_{10}$ は水面上 $10 \mathrm{~m}$ の風速 $(\mathrm{m} / \mathrm{s}), \mathrm{h}$ は水深 (m)， $\mathrm{C}_{\mathrm{f}}$ は水面での摩擦係数である. 本モデルでは鉛直 瀜動粘性係数として式(33)を用いた.

次に，水平渦動粘性係数 $\mathrm{A}_{\mathrm{h}}$ について検討した。 この 係数は，経験的に定めることが多く，沿岸の現象では $10^{4} \sim 10^{6} \mathrm{~cm}^{2} / \mathrm{s}$ 程度, 海洋の大循環では $10^{7} \sim 10^{8} \mathrm{~cm}^{2} / \mathrm{s}$ 程度の值が使用されている. Hidaka ${ }^{8)}$ は海洋の大循環 に関する問題で, 海流の流速と水平渦動粘性俰数 $A_{\mathrm{h}}$ は ほぼ逆比例し， $A_{\mathrm{h}}$ に $10^{9} \mathrm{~cm}^{2} / \mathrm{s}$ 程度を用いると実際に近 い流速を与えるとしている.ここでは，この倸数を詳細 に検討するためにモデル海を設定し，x方向に一様で定 常な風速（10 m/s）の風が吹いて定常状態に達した場合 の水平流速の鈆直分布を求め, $\mathrm{A}_{\mathrm{h}}$ の適当な範囲を求めた. その結果, 水平スケールが $10 \mathrm{~km} \times 10 \mathrm{~km}$ のモデルでは, $5 \times 10^{4} \sim 5 \times 10^{5} \mathrm{~cm}^{2} / \mathrm{s}$, また水平スケールが $1000 \mathrm{~km} \times$ $1000 \mathrm{~km}$ の大規模なモデルでは, $10^{8} \sim 5 \times 10^{10} \mathrm{~cm}^{2} / \mathrm{s}$ 程 度の值が $A_{\mathrm{h}}$ として適当であることがわかった。

次に水平流の分布特性について検討寸る. 解析解であ る式(6)をみると，風応力の直接の作用により生じた吹 送流の部分 $\vec{u} 1$ と curl ${ }_{z} \vec{\tau}_{w}$ を含んだ鉛直方向に一様な傾 斜流の部分 $\vec{u} 2$ の 2 つに分離できる. 今, 水平スケール 
（a）吹送流

$\vec{u} 1$

（b）風成流

(吹送流十傾斜流)

$\vec{u} 1+\vec{u} 2$
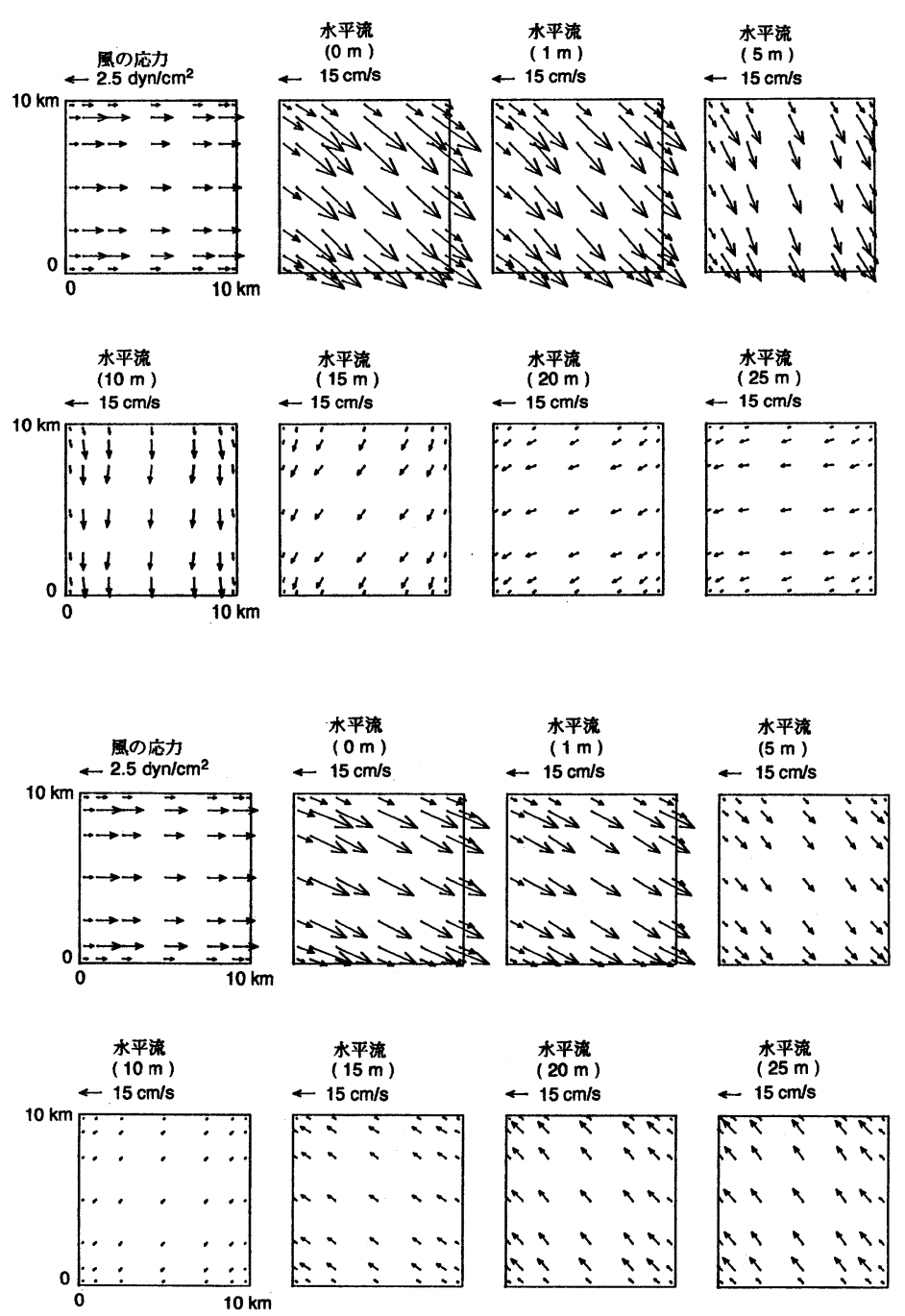

图一2 水平流の分布 ( 水深 $\mathrm{h}=25 \mathrm{~m}, \mathrm{~A}_{\mathrm{h}}=10^{5} \mathrm{~cm}^{2} / \mathrm{s}$ )

が10 km×10 km のモデル海を設定し，上記の方法で渦 動粘性俰数を仮定して東方向に一様で定常な風速（10 $\mathrm{m} / \mathrm{s}$ ）の風が吹いて定常状態に達した場合の水平流速の 鉛直分布を計算した。水深 $\mathrm{h}$ は摩擦深度 D より浅い場 合 $(25 \mathrm{~m})$ と深い場合 $(100 \mathrm{~m})$ の 2 ケースについて 行った. その結果を吹送流の部分 $\vec{u} 1$ と吹送流と傾斜流 の合成流である風成流 $(\vec{u} 1+\vec{u} 2)$ に分けて图一2（水深 $25 \mathrm{~m}$ ）と图一3（水深 $100 \mathrm{~m}$ ）に示寸. これらの図より $\vec{u} 1$ と $(\vec{u} 1+\vec{u} 2)$ を比較すると, 表面近くでは両者に大 きな差はないが，深部では大きく流速分布の異なること がわかる． $\vec{u} 1$ では水深が摩擦深度より小さいと底面付 近でも表面流と逆向きの流れは生じないし，水深が摩擦 深度を越えてこれが生じても，それは非常に小さい：こ れに対して $(\vec{u} 1+\vec{u} 2)$ は水深の半分程度の深さで表面流 とは逆向きの流れとなっており，それ以深では著しい北 向き成分がでている.これは，上層で吹送流による南方
へのエクマン輸送に対して，下層で北方への体積輸送の あることを示し, 風成流の鉛直循環の存在を示している.

\section{5. 実際の風成流との比较}

大村湾（平均水深 $18 \mathrm{~m}$ ) において, 風成流の現地観 測が行われている ${ }^{9}$ ．その結果によると，湾の下層部で は風が吹き始めると遅れ時間が約 3 時間で風の方向に対 して時計回りに約 240 度の流れが起こっている. 前項 で検討したモデル (水平スケールが10 km×10 kmで水深 が25 m) でこの層の流向をみると，220２60 度であり， 現地観測結果と解析解がほぼ一致している.

\section{6. 結語}

解析解を求める過程で式(16)のような条件を課してい る. したがって，任意風系に適用するにはこの条件によ 
（a）吹送流
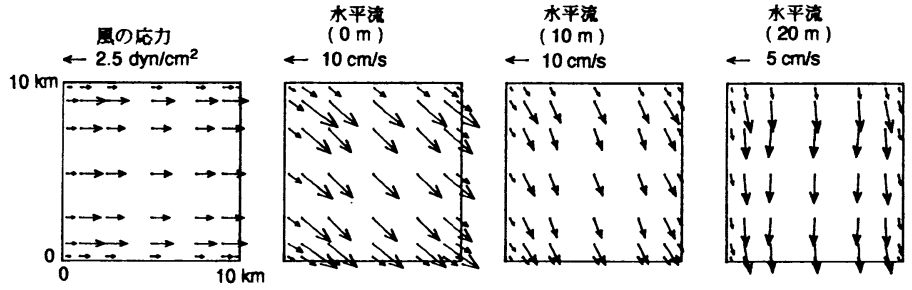

$\vec{u} 1$
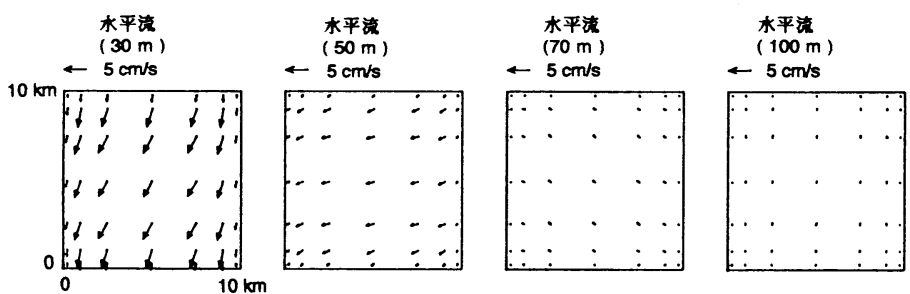

（b）風成流
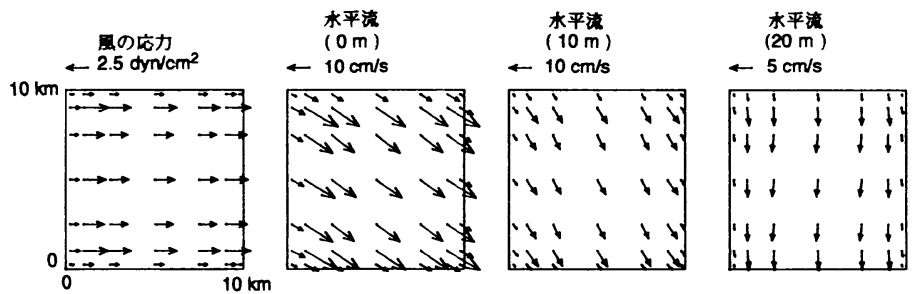

$$
\begin{gathered}
\text { （吹送流 }+ \text { 傾斜流） } \\
\vec{u} 1+\vec{u} 2
\end{gathered}
$$
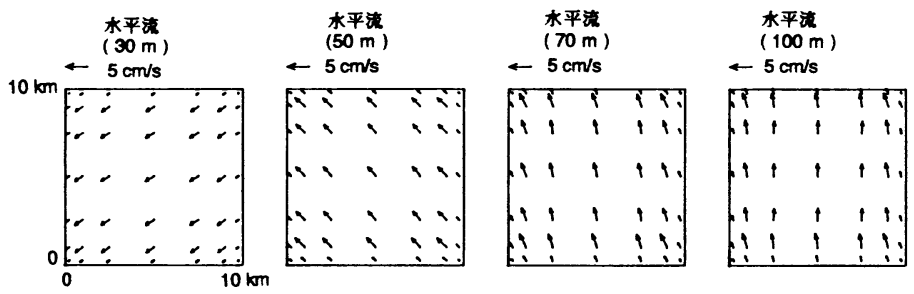

图一3 水平流の分布 ( 水深 $\mathrm{h}=100 \mathrm{~m}, \mathrm{~A}_{\mathrm{h}}=10^{5} \mathrm{~cm}^{2} / \mathrm{s}$ )

る影韹について検討することが必要である。しかしなが ら，風の回転㕮果のない風系を与える場合には，この条 件は成立しており，求めた解を実際の海城に適用可能で ある. 特に浅い海域でも流れの鉛直循環の存在を示唆し ており, 数 $\mathrm{km}$ から数百 $\mathrm{km}$ 程度の水平スケールで矩形 に近い内湾，内海や湖沼の風成流の基本特性を知ること に適用できると考えられる.

期辞 : 本研究に際し, 東京水産大学名誉教授斎藤泰一先 生，同大教授松山優治先生に様々なご教示を頂いた。 ま た，長崎大学懪境科学部中村武弘助教授には貴重な資料 をご提供頂いた。記して謝意を表す。

\section{考文获}

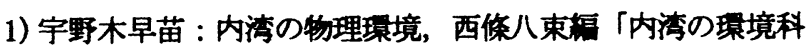
学」, pp. 63-162, 培風館, 東京, 1984.

2）長島秀樹：傾いた底を持つ水道の吹送流，理研報告，54, pp. 23-27, 1982.
3）中村,富植，飯塚，小田，三局：大村唀の潮流に関寸る研究 (3), 長崎人学工学部研究報告, 21巻, 37号, pp. 179-187, 1991.

4) Donishi, Y. and Imazato, N. :Study on the currents in Lake Biwa (2)- Barotoropic responses to the uniform wind of a finite duration - , J. Oceanog. Soc. Japan, 31 , pp. 53-60, 1975.

5) 鳥羽良明 : 海面境界過程, 海洋科学基礶講座「海洋物理 I」 , pp. 145-255, 東海大学出版，東京, 1970.

6) 松本，羽田野，斑藤 : 閉銧性水域における定常風成流の解析解 について, 土木学会年粪49回第2部B, po. 700-701, 1994.

7) 余越, 富所：風による做訪湖の流動特性，土木学会論文集, 第276号, pp. 53-63， 1978.

8) Hidaka, K. : How faithfully will the geostrophic currents represent the existing ocean currents ?, J. Oceanog. Soc. Japan, 28, pp. 48-62, 1972.

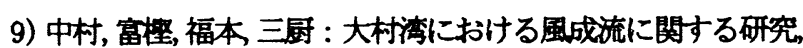
海岸工学論文集, 39, pp. 246-250, 1992.

(1999. 9. 30受付) 